\title{
Role of prior experience in blocking the disruptive effects of neuroleptic drugs on active avoidance by rats
}

\author{
JAMES R. BLACKBURN and ANTHONY G. PHILLIPS \\ University of British Columbia, Vancouver, British Columbia, Canada
}

\begin{abstract}
Administration of moderate doses of neuroleptic drugs prevents the acquisition of active avoidance responding. However, equal doses may have little or no impact on the performance of a previously acquired response. Three experiments with rats were performed to examine the effect of different pretraining regimens on protection from the disruptive effects of the neuroleptic drug metoclopramide $(5.0 \mathrm{mg} / \mathrm{kg}$ ). Experiment 1 demonstrated that, following 10 noncontingent pairings of a tone warning signal (WS) and footshock, metoclopramide treatment prevented response acquisition but did not significantly disrupt the performance of rats that had been given a single training session of five avoidance trials, or even a single escape training session in which avoidance was prevented prior to shock onset. Experiment 2 demonstrated that escape training provided no protection if rats were drugged at the time of training. Experiment 3 replicated Experiment 2 , except that the training procedure was modified by the absence of the WS and a decreased time before shock onset. These results suggest that in order to be protected from neuroleptic effects, rats need only a minimal amount of experience associating the experimental context with the production of active responses.
\end{abstract}

Both the performance and the acquisition of avoidance behaviors can be disrupted by neuroleptic drug treatment. However, despite the conspicuous ability of neuroleptics to disrupt the performance of a previously acquired active avoidance response, there is strong evidence that they have a qualitatively greater effect on the acquisition of a new response. Several studies have demonstrated that doses of neuroleptic drugs that prevent acquisition of a new avoidance response may have a greatly reduced effect on the performance of a previously acquired response (Anisman, Irwin, Zacharko, \& Tombaugh, 1982; Beninger, Phillips, \& Fibiger, 1983; Blackburn \& Phillips, 1989; Carey \& Kenney, 1987; Fibiger, Zis, \& Phillips, 1975; Ray \& Bivens, 1966).

Acquisition of active avoidance has also been studied after selective disruption of central dopamine neurotransmission following treatment with the neurotoxin 6hydroxydopamine (6-OHDA). These studies have consistently reported a substantial disruption of acquisition of active avoidance (Cooper, Breese, Grant, \& Howard, 1973; Delacour, Echavarria, Senault, \& Houcine, 1977; Fibiger, Phillips, \& Zis, 1974; Heybach, Coover, \&

This research was funded by a grant from the Medical Research Council of Canada (PG-23). James Blackburn was supported by a Studentship from the Medical Research Council of Canada. James Blackburn is presently at the Clinical Brain Disorders Branch, NIMH-St. Elizabeth's Hospital, Washington, DC 20032. Correspondence concerning this article may be addressed to A. G. Phillips, Department of Psychology, University of British Columbia, Vancouver, British Columbia V6T 1W5, Canada.

-Accepted by previous editor, Lynn Nadel
Lints, 1978). Several studies have indicated that 6-OHDA lesions can also disrupt performance of a previously acquired response (Beer \& Lenard, 1975; Cooper et al., 1973; Lenard \& Beer, 1975; Neill, Boggan, \& Grossman, 1974). However, no deficit was observed when rats received extensive training prior to the lesion (Fibiger et al., 1975).

What is clear from both the pharmacological and the lesion studies is that if an animal has had sufficient avoidance training prior to disruption of dopamine neurotransmission, the impact of the treatment on performance is markedly attenuated. What elements of the previous experience are essential for this prophylactic effect remain to be specified.

Previous studies have clearly established that neuroleptic-treated animals are not deficient in associating a warning signal (WS) and an aversive stimulus (AS) (Beninger, Mason, Phillips, \& Fibiger, 1980a; Davidson \& Weidley, 1976; Fibiger et al., 1975; Posluns, 1962). ${ }^{1}$ In fact, rats that fail to avoid while treated with neuroleptics can subsequently acquire an avoidance response or display other appropriate responses to shock-related stimuli even if no further shocks are presented (Beninger, MacLennan, \& Pinel, 1980; Beninger, Mason, Phillips, \& Fibiger, 1980a, 1980b). In addition, Anisman et al. (1982) found that administration of pimozide at the time of pairings of the WS and the AS did not disrupt the subsequent facilitatory effect such pairings have on the acquisition of avoidance responding (De Toledo \& Black, 1967; Overmier \& Leaf, 1965; Weiss, Kriekhaus, \& Conte, 1968). Thus, the neuroleptic drug did not prevent the formation of a Pavlovian WS-AS association when 
administered during conditioning. On the other hand, Anisman et al. (1982) found, in an additional experiment, that if pimozide was administered at the time of avoidance training, there was no protection from neuroleptic effects as a result of prior WS-AS pairings. These results indicate that Pavlovian association of the WS and the AS is one element of the avoidance training experience that may be required for response acquisition, but that this element is not in itself mediated by dopaminergic mechanisms, nor is it sufficient to permit a neuroleptic-treated rat to perform avoidance responses.

It has been proposed that neuroleptics are ineffective against established avoidance responses because responding has become automatized through overtraining (Fibiger et al., 1975; Kimble \& Perlmuter, 1970). Alternatively, given the suggestion that fear is required for the acquisition of avoidance responding but not its maintenance (Mineka, 1979; Seligman \& Johnston, 1973), an alternative hypothesis is that dopamine mediates fear, or the capacity for fear to affect avoidance responding. These hypotheses would be challenged by evidence that neuroleptic effects can be diminished by minimal levels of pretraining. Previous studies of the prophylactic effects of low levels of pretraining have reported inconsistent results. Fibiger et al. (1975) found that 2 days of pretraining, with 10 trials per day, did not prevent disruption of responding by $0.15 \mathrm{mg} / \mathrm{kg}$ haloperidol, although rats continued to perform flawlessly when given this dose after 9 days of training. In contrast, Beninger et al. (1983) found protection from the effects of 0.5 or $1.0 \mathrm{mg} / \mathrm{kg}$ pimozide following 2 days of training ( 10 trials per day).

In the experiments reported below, we examined the capacity of minimal avoidance pretraining procedures to provide protection from neuroleptic effects on one-way avoidance. In order to further minimize the amount of training required, the WS-AS association was instilled in rats prior to training. As noted above, such treatment facilitates the development of protection from neuroleptic effects, even though Anisman et al. (1982) found that it is not sufficient to produce protection by itself.

An additional question to be addressed is whether a rat must actually perform the avoidance response prior to drug testing in order for protection to develop. All rats, drugged or undrugged, perform escape responses following shock onset on acquisition trials in which they fail to avoid. On the basis of this observation, escape training would not be expected to be sufficient treatment to instill protection.

In the experiments reported in this paper, we employed the neuroleptic drug metoclopramide, a substituted benzamide whose long-term use is associated with severe extrapyramidal side effects (Bateman, Rawlins, \& Simpson, 1985; Harrington et al., 1983; Indo \& Ando, 1982). We have previously determined that metoclopramide has a profile of action similar to that of classical neuroleptics in the disruption of one-way avoidance (Blackburn, 1989; Blackburn \& Phillips, 1989) and in the attenuation of conditioned appetitive responses (Blackburn, Phillips, \& Fibiger, 1989).

\section{EXPERIMENT 1}

In the first experiment, we examined the ability of metoclopramide-treated rats to perform one-way avoidance responses following minimal amounts of pretraining. In order to minimize the amount of pretraining required, all rats were given 10 pairings of the tone WS and the shock AS on the day prior to training. Such treatment facilitates avoidance acquisition, but is not in itself sufficient to provide protection from neuroleptic effects (Anisman et al., 1982; Blackburn, 1989).

There were three pretraining regimens in Experiment 1. In the avoidance training regimen, the rats received five avoidance trials. This provides a low level of training that is near the threshold required to acquire a one-way avoidance response (Bolles, 1975). In the escape training regimen, trials were similar to those of avoidance training, but the rats were prevented from crossing into the safe compartment by keeping the guillotine door shut until shock onset. This treatment provided experience similar to that of neuroleptic-treated rats during avoidance training, where avoidance does not occur in the presence of the WS, but escape responses are elicited soon after shock onset. The control regimen consisted of no pretraining.

On the test day, all rats were treated with $5.0 \mathrm{mg} / \mathrm{kg}$ metoclopramide, a dose sufficient to prevent acquisition of one-way avoidance by naive rats (Blackburn, 1989; Blackburn \& Phillips, 1989).

\section{Method}

Subjects. Male hooded rats obtained from Charles River Laboratories of Canada were used. All rats were experimentally naive and weighed $300-600 \mathrm{~g}$ at the start of the experiment. The rats were housed in single cages at least 1 week prior to the beginning of training and were handled at least three times during that period. The climatically controlled colony room was on a standard $12-\mathrm{h}$ light-dark cycle (lights on at $0800 \mathrm{~h}$ ). Each experimental session occurred between 0900 and $1300 \mathrm{~h}$.

Apparatus. Pavlovian conditioning of the WS-AS association was conducted in a Plexiglas chamber, $26 \times 30 \times 40 \mathrm{~cm}$ high. The walls of the compartment were lined with brown shelf paper, making them translucent. A hinged Plexiglas ceiling remained transparent. The grid floor could be electrified by a scrambled 1.0-mA dc current (BRS/LVE shock generator). A $2900-\mathrm{Hz}$ tone generator (Sonalert) was centered $8 \mathrm{~cm}$ above the shock grid. The avoidance apparatus consisted of a shuttlebox $(25 \times 78 \times 33 \mathrm{~cm}$ deep) divided into two equal halves by a partition. Both halves were painted flat black. The partition could be opened by raising a 13-cm-wide guillotine door. A grid floor on one side (the "shock" side) could be connected to the same shock generator as the conditioning apparatus. A tone generator identical to that in the conditioning apparatus was mounted below the grid floor at the end of the shock side. Electomechanical relays and timers were used for stimulus control and data collection. Metoclopramide- $\mathrm{HCl}$ (Sigma) was dissolved as $5.0 \mathrm{mg}$ of the salt weight in $1.0 \mathrm{ml}$ of saline. The drug was injected intraperitoneally $60-90 \mathrm{~min}$ prior to the start of the test session.

Avoidance training. Each avoidance session began by putting the rat into the "safe" (nonelectrified) side of the shuttlebox. After $30 \mathrm{sec}$, the rat was placed on the shock side, facing away from the guillotine door. The trial began with tone onset and the opening of the door. If the rat moved into the safe side during the 
10-sec tone period, the tone was turned off, the door was lowered, and an avoidance response was recorded. If the rat failed to avoid during the 10-sec tone period, the offset of the tone was contiguous with the onset of the footshock. Movement into the safe side was followed by lowering the door, and an escape response was recorded. If no response occurred within $10 \mathrm{sec}$ following shock onset, the rat was pushed gently into the safe side and was assigned a response latency of $20 \mathrm{sec}$. Entry into the safe side always initiated the next 30 -sec intertrial interval.

Escape training. The escape training sessions were identical to avoidance trials in all respects except that the guillotine door remained shut during WS presentation, preventing avoidance. The door was opened only at the onset of the AS. Response latencies were recorded as in avoidance trials.

Procedure. The rats were randomly assigned to one of six groups ( $n=6$ per group). On Day 1, each group of rats received 10 noncontingent tone-shock pairings in the Plexiglas compartment. Each pairing consisted of a $10-\mathrm{sec}$ presentation of the tone, followed by a $1.5-\mathrm{sec}, 1.0-\mathrm{mA}$ footshock. On the next day, the training day, the two control groups received no treatment. The avoidance groups both received five standard avoidance trials. The number of avoidances and the response latencies did not differ between these two groups $(F \mathrm{~s}<1)$. The escape groups both received five escape training trials. The mean latency to escape following shock onset was $3.1 \mathrm{sec}$ for Group Esc-Sal and $3.5 \mathrm{sec}$ for Group Esc-Met $(F<1)$. The test day (Day 3) consisted of 10 trials; one of each pair of groups received saline, the other $5.0 \mathrm{mg} / \mathrm{kg}$ metoclopramide.

Statistical analysis. The number of avoidances in the test session were analyzed using a two-way (training $\times$ drug) ANOVA. Latency scores were analyzed with a three-way (training $\times$ drug $x$ trial) ANOVA. In each case, significant effects were further analyzed using Newman-Keuls post hoc tests at a .05 level of significance.

\section{Results}

The rats that received prior avoidance training were able to avoid on the test day despite metoclopramide treatment, whereas those that received no prior training were not. Importantly, the rats that received escape training performed as well or better than those that received avoidance training. The number of avoidance responses performed by each group are illustrated in the top panel of Figure 1 . There was a significant effect of training $[F(2,30)=$ $62.01, p<.001]$, a significant effect of drug $[F(1,30)=$ $20.19, p<.001]$, and a significant training $\times$ drug interaction $[F(2,30)=3.78, p<.05]$. The post hoc tests revealed that only in the case of the control groups was the performance of the metoclopramide-treated group significantly worse than that of the saline-treated group. Following avoidance or escape training, the rats were protected from the avoidance-disrupting effects of metoclopramide. A comparison of the performance of the two saline-treated groups revealed that naive rats displayed fewer avoidances than did those that had received prior avoidance or escape training.

The latency scores, illustrated in the bottom panel of Figure 1, reveal a similar pattern of results. However, in this case, the effects can be attributed to significant main effects of training $[F(2,30)=34.28, p<.001]$ and drug $[F(1,30)=15.41, p<.001]$. There was no significant training $\times$ drug interaction $(F<1)$. It is interesting to note that post hoc examination of the training effect revealed that the rats that received escape training had
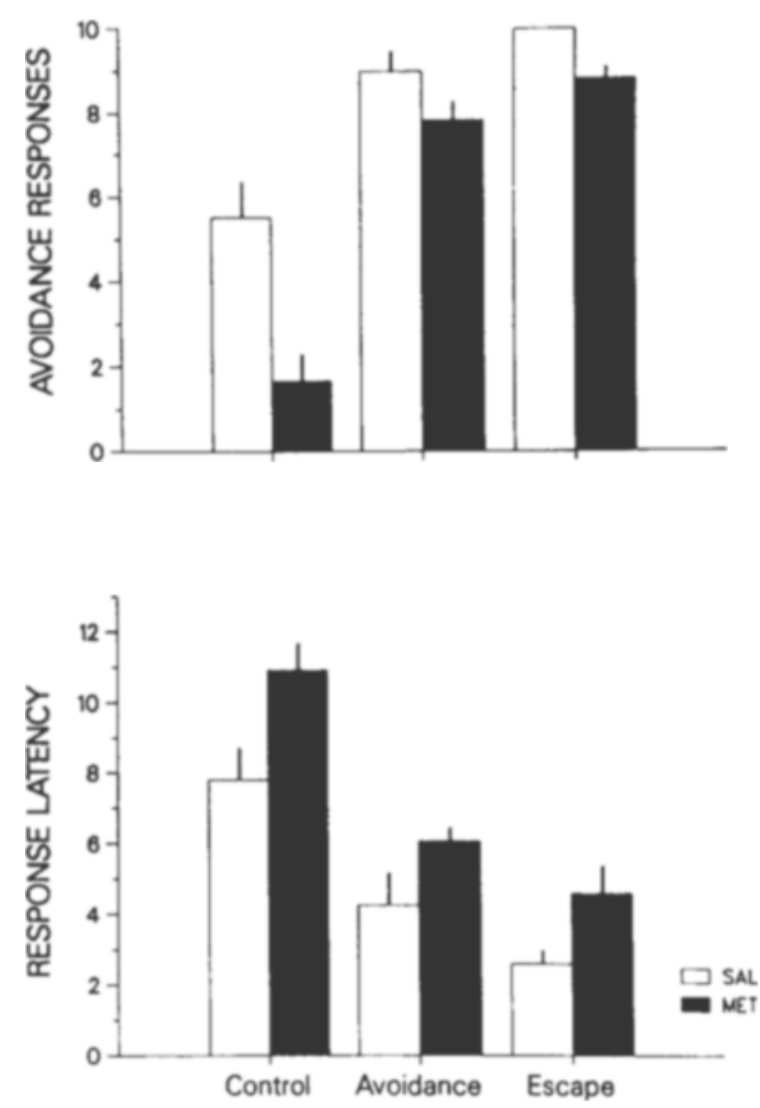

Figure 1. Mean number of avoidances $( \pm S E M)$ on the test day (top panel) and mean response latency $( \pm S E M)$ in seconds (bottom panel) in Experiment 1. On the day prior to testing, the avoidance groups received five avoidance training trials, the escape groups received five escape training trials, and the control groups were not trained. On the test day, all rats were tested for 10 trials. Met groups received $5.0 \mathrm{mg} / \mathrm{kg}$ metoclopramide, Sal groups received saline on the test day.

shorter response latencies on the test day than did the rats that had received prior avoidance training.

\section{Discussion}

This experiment indicates, in agreement with Anisman et al. (1982), that providing rats with $10 \mathrm{WS}$-AS pairings is not sufficient to provide protection from the neuroleptic effects of metoclopramide. Group Cont-Met had received 10 such pairings, but unlike the rats in Group Avoidance-Met, they did not receive additional avoidance training prior to the test day. On the test day, Group ContMet failed to acquire the avoidance response (successfully executing only 1.7 of 10 avoidance responses), whereas Group Avoidance-Met was able to avoid on 7.8 of 10 trials.

This experiment also indicates that protection from the effects of a neuroleptic can be achieved after a very small amount of pretraining. Metoclopramide-treated rats that had received only five escape training trials following a prior conditioning session consisting of $10 \mathrm{WS}-\mathrm{AS}$ pair- 
ings were able to execute 8.8 of 10 successful avoidance responses. This argues strongly against the notion that the protection from neuroleptic effects observed after pretraining is the result of overlearning through extensive response repetition. Indeed, the rats of Group AvoidanceMet managed only an average of 1.3 avoidance responses on the training day. This pattern of results seems to suggest that protection from neuroleptic effects is acquired abruptly, rather than accumulated in an incremental fashion.

Perhaps the most striking finding of this experiment was the protection from the disruptive effects of neuroleptic treatment that developed in the absence of any prior opportunity to execute an avoidance response. Execution of five escape responses in the same apparatus, using the same WS, had an effect identical to that observed when the rats were able to make avoidance responses. This is an important finding, as it rules out several hypotheses concerning the origin of the protection from neuroleptic effects. First, it excludes the possibility that the avoidance response becomes insensitive to neuroleptic effects through overtraining of the avoidance response per se: avoidance, occurring prior to shock onset, was a novel response for the rats in Group Esc-Met on the test day. Second, because the rats had only escaped from shock on prior trials, dopamine blockade could not have disrupted the generalization of the escape response to an avoidance response. Third, the ability of rats to perform the avoidance response while drugged could not have been due to an incrementally established association between performing the response and precluding shock onset. Rather, the rats appear to have been basing their responses on an expectation that the safe compartment was related to the nonoccurrence of shock. This suggests that dopamine interacts with cognitive mechanisms, as opposed to response-reinforcement mechanisms, in the establishment of behavior.

\section{EXPERIMENT 2}

The protection against the disruptive effects of subsequent neuroleptic treatment following escape training observed in Experiment 1 was unexpected. Previous research has shown that escape behavior occurring during avoidance acquisition with neuroleptics does not enhance an animal's subsequent ability to avoid while drugged (Beninger et al., 1983; Fibiger et al., 1975). These findings suggest that critical information regarding the avoidance task may be acquired during escape trials if dopamine function is normal, and that once this information is encoded it can subsequently influence the performance of rats treated with dopamine antagonists. If this is the case, then metoclopramide treatment during escape training should attenuate the protective effects of training against disruption of avoidance acquisition by a neuroleptic. This hypothesis was tested in Experiment 2.

\section{Method}

Subjects and Apparatus. Subjects similar to those of the previous experiment were used; all conditioning, training, and testing was conducted in the same apparatus.

Procedure. The rats were randomly assigned to one of three groups ( $n=8$ per group). On Day 1 , the rats of each group received 10 noncontingent WS-AS pairings in the Plexiglas conditioning compartment, as described in Experiment 1 . On the next day, the control group received no treatment, whereas Groups Esc-Met and EscSal received five escape training trials, also as described in Experiment 1. For Group Esc-Sal, this escape training occurred following the administration of saline, whereas for Group Esc-Met, training occurred following the administration of $5.0 \mathrm{mg} / \mathrm{kg}$ metoclopramide. The escape latencies for these two groups did not differ on the training day $(F<1)$. On the test day (Day 3), the rats of each group received $5.0 \mathrm{mg} / \mathrm{kg}$ metoclopramide and were tested for 10 avoidance trials.

Statistical analysis. The number of avoidances were analyzed using a one-way (training) ANOVA. Latency scores were analyzed using a two-way (training $\times$ trial) ANOVA. In each case, significant effects were further analyzed using Newman-Keuls post hoc tests at a .05 level of significance.

\section{Results}

The rats that received escape training following saline administration (Group Esc-Sal) were able to avoid successfully on the test day despite the administration of metoclopramide. However, the rats that received identical escape training following metoclopramide administration (Group Esc-Met) were not protected from the effects of metoclopramide on the following day. The number of avoidances executed by these two groups, as well as by the control group that received no escape training, are illustrated in the top panel of Figure 2. The ANOVA indicated that there was a significant difference between the number of avoidance responses executed by the rats of the three groups $[F(2,21)=23.47, p<.001]$. Post hoc testing revealed that the group that received escape training following saline (Group Esc-Sal) avoided significantly more often than the other two groups on the test day.

The latency scores are shown in the bottom panel of Figure 2. Again, there was a significant effect of group $[F(2,21)=13.83, p<.001]$. Post hoc tests indicated that the group trained under saline (Group Esc-Sal) had lower latencies than either of the other two groups.

\section{Discussion}

The performance of Group Esc-Met in this experiment confirmed the major finding of Experiment $1-$ specifically, that five escape trials constitute sufficient training to provide protection from the disruptive effects of metoclopramide on the performance of avoidance behaviors. In addition, the present results extend the previous findings to demonstrate that such escape training is not effective when delivered to neuroleptic-treated rats.

The latter observation is consistent with the finding that neuroleptic-treated rats are incapable of acquiring an avoidance response over several days of training (Beninger et al., 1983; Blackburn \& Phillips, 1989; 

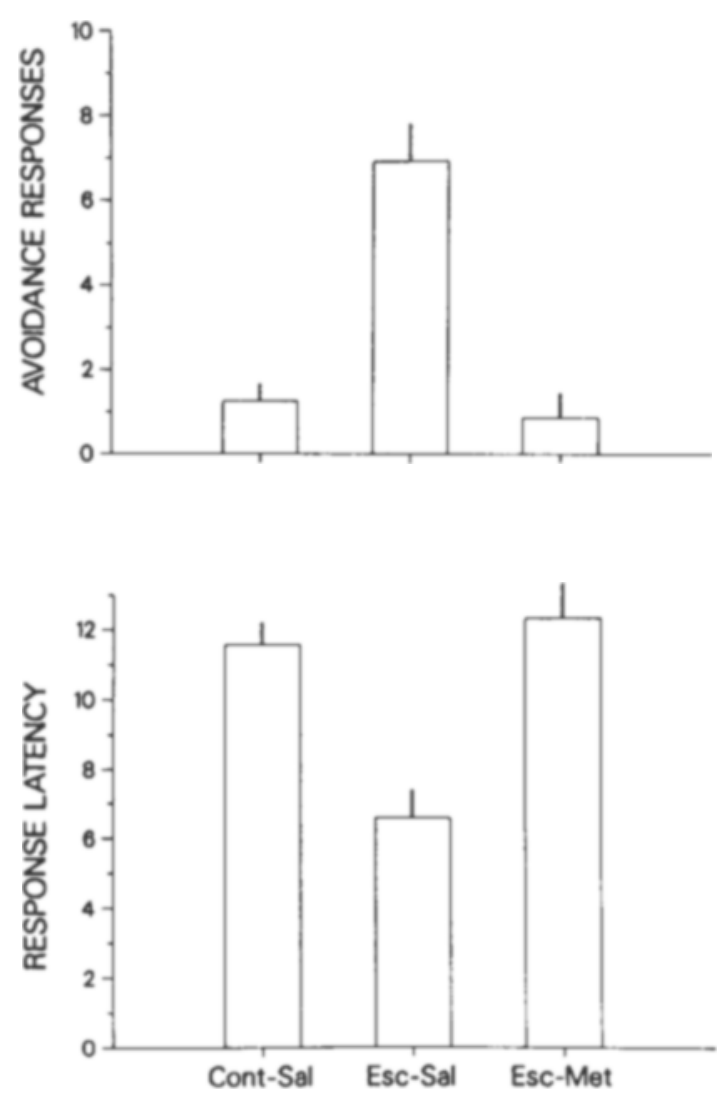

Figure 2. Mean number of avoidances $( \pm S E M)$ on the test day (top panel) and mean response latency $( \pm S E M)$ in seconds (bottom panel) in Experiment 2. On the day prior to testing, Group ContSal was not trained and Groups Esc-Sal and Esc-Met received five escape training trials. Group Esc-Met received $5.0 \mathrm{mg} / \mathrm{kg}$ metoclopramide, and Group Esc-Sal received saline on this day. On the test day, all rats received $5.0 \mathrm{mg} / \mathrm{kg}$ metoclopramide.

Fibiger et al., 1975). In each case, the rats were exposed to the same warning and aversive stimuli, in each case they exited from the compartment after the onset of the shock, and in each case they experienced these events under the influence of metoclopramide. What remains surprising is the ability of neuroleptic-treated rats to avoid on the day following escape training if they had not been given metoclopramide prior to the training trials. During escape training, both groups received identical experimental contingencies, and the responses of each were indistinguishable during the training trials. Yet on the test day, only Group Esc-Sal was able to benefit from the experience of the training day.

\section{EXPERIMENT 3}

It is conceivable that a critical factor for the outcome of Experiment 2 was the long delay between tone presentation and shock onset in escape training trials. It was noted that over the five escape training trials, the rats typically came to stand by the closed guillotine door, sniff- ing and clawing at it. That is, they appeared to be attempting to avoid, even though they could not get to the safe side because of the closed guillotine door. Perhaps subsequent reinforcement of these attempts when escape ultimately occurred was the critical component of the procedure that required dopaminergic mediation. Accordingly, in Experiment 3, we examined the effect of giving escape training in the absence of WS presentations, and without giving the rats sufficient time to orient to the door prior to shock onset.

\section{Method}

Subjects and Apparatus. Subjects similar to those of the previous experiments were used, and were tested in the same apparatus.

Procedure. The rats were randomly assigned to one of three groups ( $n=6$ per group). On Day 1, the rats of each group received 10 noncontingent WS-AS pairings in the Plexiglas conditioning compartment, as described in Experiment 1. On the next day, Group Cont-Sal received no treatment, whereas Group Esc-Met and Group Esc-Sal received five escape training trials. In the present experiment, the escape training procedure was modified to limit the opportunity of the rat to perform any response prior to shock onset. First, the WS (tone) was not presented at all on the escape training day. Second, the interval between placing the rat in the shock side of the compartment and the onset of shock was reduced from 10 to $1 \mathrm{sec}$, although shock onset remained synchronous with the opening of the guillotine door. The rats that received saline prior to escape training had a mean response latency of $2.1 \mathrm{sec}$; those that received metoclopramide had a mean latency of $3.3 \mathrm{sec}[F(1,10)=$ $5.64, p<.05]$. On the test day, all rats received $5.0 \mathrm{mg} / \mathrm{kg}$ metoclopramide and were tested for 10 avoidance trials.

Statistical analysis. The data were analyzed using the ANOVA and Newman-Keuls post hoc test, as described in Experiment 2.

\section{Results}

As shown in the top portion of Figure 3, the rats that had received the reduced form of escape training while undrugged were able to avoid on 7.3 of 10 trials on the test day despite metoclopramide treatment. In contrast, those that had received escape training under the influence of metoclopramide were only able to avoid on 1.5 of 10 trials, no more than untrained controls (also 1.5 of 10).

The ANOVA indicated that there was a significant difference between the number of avoidance responses executed by the rats of the three groups on the test day $[F(2,15)=12.71, p<.001]$. Post hoc tests revealed that the group that had received escape training following metoclopramide treatment avoided significantly more often than either of the other two groups.

The latency scores are shown in the bottom panel of Figure 3. Again, there was a significant effect of training $[F(2,15)=7.26, p<.01]$. Post hoc tests indicated that the group given escape training under saline (Group Esc-Sal) had lower latencies than the other two groups.

\section{Discussion}

Once again, as in Experiment 2, we observed that rats trained for five escape trials prior to being tested on avoidance showed remarkable resilience to the effects of metoclopramide treatment, but only if they had received the escape training in the absence of the drug. If the rats 

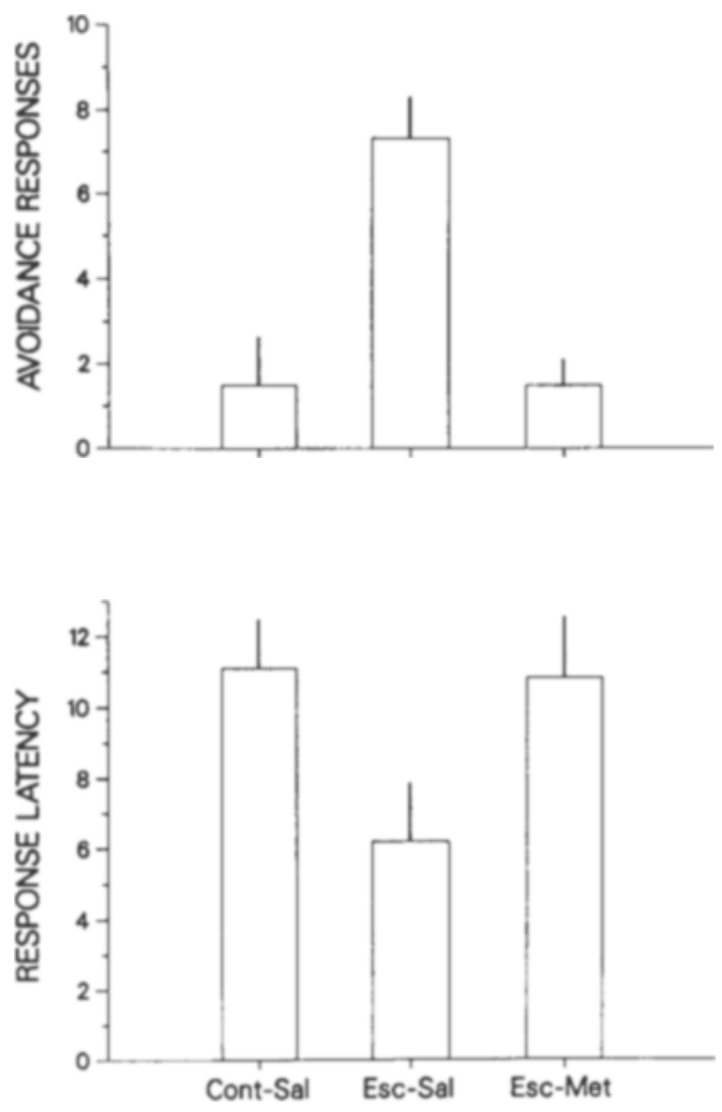

Figure 3. Mean number of avoidances $( \pm S E M)$ on the test day (top panel) and mean response latency $( \pm S E M$ ) in seconds (bottom panel) in Experiment 3. On the day prior to testing, Group ContSal was not trained and Groups Esc-Sal and Esc-Met received five escape training trials with the warning signal absent and a delay of 1 sec between placement in the shock side of the box and shock onset. During training, Group Esc-Met received $5.0 \mathrm{mg} / \mathrm{kg}$ metoclopramide, and Group Esc-Sal received saline. On the test day, all rats received $5.0 \mathrm{mg} / \mathrm{kg}$ metoclopramide.

had received identical training following the administration of metoclopramide, their performance was indistinguishable from that of rats that had received no prior training.

In this case, escape training amounted to little more than putting the rats into the shock side of the compartment, turning on the shock, and letting them run out again. Yet something that happened during those five trials was sufficient to provide the rats with the experience they required to be able to perform avoidance responses while drugged on the following day.

\section{GENERAL DISCUSSION}

These experiments demonstrate just how little training is required to produce a dramatic attenuation of the effects of metoclopramide on avoidance behavior. Following the administration of metoclopramide, a naive rat will not respond to a WS by exiting the shock compartment; it remains in the compartment until the shock comes on and then escapes. In contrast, rats that have executed as few as five avoidance or escape responses, even in the absence of the stimulus that normally signals shock, are subsequently able to initiate avoidance responses successfully despite administration of the same dose of metoclopramide.

In each of Experiments 2 and 3, there were substantial differences between the test performance of the two groups that had received escape training with or without metoclopramide on the training day. This was the case even though the rats of both groups were exposed to identical experimental contingencies on the training day and both performed escape responses. The differences in test performance suggest that the saline-treated rats were influenced by a specific experience during the course of escape training that provided them with protection from the disruptive effects of metoclopramide during subsequent testing, and that metoclopramide administration prior to training blocked this effect. The problem in interpretation lies in determining what the critical event was that the saline-treated rats experienced, and in specifying how metoclopramide treatment altered this process.

First, consider what saline-treated rats might learn on the training day. In recent years, several theorists have suggested that the mammalian brain can support divergent forms of learning. In particular, it has been proposed that there are two broad categories of learning, one consisting of the development of cognitive representations, or maps, the other consisting of the reinforcement of stimulus-response habits (Hirsh, 1980; Mishkin \& Petri, 1984; O'Keefe \& Nadel, 1978). Interpretation of avoidance responding in terms of stimulus-response learning, as in the model of Mowrer (1947), has been found wanting by contemporary students of avoidance (e.g., Bolles, 1975; Masterson \& Crawford, 1982; Mineka, 1979; Seligman \& Johnston, 1973). A stimulus-response account of avoidance learning seems especially inadequate to account for the present findings, in which very high levels of performance were associated with minimal levels of training. The ability of rats to withstand neuroleptic effects after so little training suggests that, rather than becoming a habit through incremental learning, the avoidance response may be a problem that the rats have solved.

If avoidance responding is mediated by a cognitively based expectation, instead of by a stimulus-response habit, we need to specify what is being represented. Mackintosh (1974), Seligman and Johnston (1973), and Toates (1982) have emphasized the importance of response learning in the acquisition of avoidance responding. That is, they see the acquisition of avoidance as being based on the establishment of an expectation that responding will result in shock omission. In contrast, Bolles (1978), relying on a substantial body of literature indicating the importance of feedback from safety signals in avoidance responding, suggested that avoidance responding is 
primarily determined by stimulus learning (learning which stimuli predict the presence or absence of shock) rather than by response learning.

As compelling as a stimulus-learning account of avoidance may be in other instances, it does not seem possible to account for the present results in those terms. The rats that received escape training were exposed to identical stimulus contingencies and experienced shock termination in the safe side of the avoidance apparatus, whether or not they received metoclopramide. Nor can it be argued that neuroleptics disrupt stimulus learning in general, given that these drugs do not disrupt the formation of Pavlovian tone-shock associations, or learning about the stimuli relevant to escape responding, as indicated by the ability of neuroleptic-treated rats to learn discriminated escape responses (Corradini, Tombaugh, \& Anisman, 1984).

The possibility that the development of protection from neuroleptic effects is based on response learning cannot necessarily be dismissed on the grounds that drugged and undrugged rats were exposed to identical response-stimulus contingencies. Although this may be the case, the small but significant difference between the escape latencies of the metoclopramide-treated and the saline-treated rats in Experiment 3 leaves open the possibility that the responses of the two groups were not equivalent. Conceivably, this may reflect a difference between performance based on an expectancy that responding will lead to shock termination on the part of the saline-treated rats, and a reflexive shock-elicited response on the part of the metoclopramide-treated rats.

The suggestion that response learning may be an important element in the development of resistance to neuroleptic effects need not imply that rats learn specific response topographies in the course of acquiring an avoidance response. Rather, the learning may be restricted to determining which of a limited repertoire of speciestypical defensive reactions is to be selected. Specifically, the appropriate learning may consist of nothing more than the development of a bias toward executing a flight response rather than a freezing response in the fearinducing environment. It seems probable that there are forebrain systems that are responsible for the elicitation of flight responses, whereas other neural systems may be responsible for freezing and autonomic responses to shock and shock-related stimuli. ${ }^{2}$

Given that the present results with metoclopramide and similar findings with other neuroleptic drugs (Beninger et al., 1983; Fibiger et al., 1975) reflect the dopamine receptor antagonist properties of these drugs, we can speculate that dopamine activity facilitates forebrain flight systems, even though dopamine is not necessary for those systems to function in all circumstances. The present data suggest that after the flight system has been engaged several times in the presence of normal dopamine function, a rat associates the environmental situation with the initiation of a flight response. Accordingly, the establishment of an association between this expectancy and the activation of the appropriate response pattern would constitute the solution to the avoidance problem. Having acquired the solution to the problem, rats are able to perform the active avoidance response even in the absence of baseline dopamine activity.

Although the present results are consistent with the idea that metoclopramide- and saline-treated groups learn different things on the escape training day, learning deficits cannot account for all effects of neuroleptic drugs on defensive behaviors. In other research (Blackburn, 1989; Blackburn \& Phillips, in press), we have found that (1) metoclopramide decreases active responding and enhances freezing responses following footshock presentation, and (2) if metoclopramide is administered to rats that have had a moderate amount of training, performance in the test session is disrupted by presentation of noncontingent footshocks, even though the same treatment does not disrupt the performance of saline-treated rats. These alterations in performance cannot be attributed to differential learning.

\section{REFERENCES}

Anisman, H., Irwin, J., Zacharko, R. M., Tombaugh, T. N. (1982). Effect of dopamine receptor blockade on avoidance performance: Assessment of effects on cue-shock and response-outcome associations. Behavioral \& Neural Biology, 36, 280-290.

Bateman, D. N., Rawlins, M. D., \& Simpson, J. M. (1985). Extrapyramidal reactions with metoclopramide. British Medical Journal, 291, 930-932.

BeER, B., \& LeNARD, L. G. (1975). Differential effect of intraventricular administration of 6-hydroxydopamine on behavior of rats in approach and avoidance procedures: Reversal of avoidance decrements by diazepam. Pharmacology, Biochemistry \& Behavior, 3, 879-886.

Beninger, R. J., Maclennan, A. J., \& Pinel, J. P. J. (1980). The use of conditioned defensive burying to test the effects of pimozide on associative learning. Pharmacology, Biochemistry \& Behavior, 12 , 445-448.

Beninger, R. J., Mason, S. T., Phillips, A. G., Fibiger, H. C. (1980a). The use of conditioned suppression to evaluate the nature of neuroleptic-induced avoidance deficits. Journal of Pharmacology \& Experimental Therapeutics, 213, 623-627.

Beninger, R. J., Mason, S. T., Phillips, A. G., Fibiger, H. C $(1980 \mathrm{~b})$. The use of extinction to investigate the nature of neurolepticinduced avoidance deficits. Psychopharmacology, 69, 11-18.

Beninger, R. J., Phillips, A. G., \& Fibiger, H. C. (1983). Prior training and intermittent retraining attenuate pimozide-induced avoidance deficits. Pharmacology, Biochemistry \& Behavior, 18, 619-624.

BLACKBURN, J. R. (1989). The role of dopamine in preparatory and consummatory defensive behaviours. Unpublished doctoral dissertation, University of British Columbia, Vancouver.

Blackburn, J. R., \& Phillips, A. G. (1989). Blockade of acquisition of one-way conditioned avoidance responding by haloperidol and metoclopramide but not by thioridazine or clozapine: Implications for screening new antipsychotic drugs. Psychopharmacology, 98, 453-459.

Blackburn, J. R., \& Phillips, A. G. (in press). Enhancement of freezing behaviour by metoclopramide: Implications for neuroleptic-induced avoidance deficits. Pharmacology, Biochemistry \& Behavior.

Blackburn, J. R., Phillips, A. G., \& Fibiger, H. C. (1989). Dopamine and preparatory behavior: III. Effects of metoclopramide and thioridazine. Behavioral Neuroscience, 103, 903-906.

Bolles, R. C. (1972). The avoidance learning problem. In G. H. Bower (Ed.), The psychology of learning and motivation (Vol. 6, pp. 97 145). New York: Academic Press.

Bolles, R. C. (1975). Theory of motivation (2nd ed.). New York: Harper \& Row. 
Bolles, R. C. (1978). The role of stimulus learning in defensive behavior. In S. H. Hulse, H. Fowler, \& W. K. Honig (Eds.), Cognitive processes in animal behavior (pp. 89-107). Hillsdale, NJ: Erlbaum.

CAREY, R. J., \& KenNEY, S. (1987). A delayed onset of haloperidol effects on learned escape and avoidance behavior. Pharmacology, Biochemistry \& Behavior, 28, 203-208.

Cooper, B. R., Breese, G. R., Grant, L. D., \& Howard, J. L. (1973). Effects of 6-hydroxydopamine treatments on active avoidance responding: Evidence for the involvement of brain dopamine. Joumal of Pharmacology \& Experimental Therapeutics, 185, 358-370.

Corradini, A., Tombaugh, T., \& Anisman, H. (1984). Effects of pimozide on escape and discrimination performance in a water-escape task. Behavioral Neuroscience, 98, 96-106.

DAvidson, A. B., \& Weidley, E. (1976). Differential effects of neuroleptic and other psychotropic agents on acquisition of avoidance in rats. Life Sciences, 18, 1279-1284.

De Toledo, L., Black, A. H. (1967). Effects of preshock on subsequent avoidance conditioning. Journal of Comparative \& Physiological Psychology, 63, 493-499.

Delacour, J., Echavarria, M. T., Senault, B., Houcine, O. (1977). Specificity of avoidance deficits produced by 6-hydroxydopamine lesions of the nigrostriatal system of the rat. Journal of Comparative \& Physiological Psychology, 91, 875-885.

Fibiger, H. C., Phillips, A. G., \& Zis, A. P. (1974). Deficits in instrumental responding after 6-hydroxydopamine lesions of the nigroneostriatal dopaminergic projection. Pharmacology, Biochemistry \& Behavior, 2, 87-96.

Fibiger, H. C., Zis, A. P., \& Phill.ips, A. G. (1975). Haloperidolinduced disruption of conditioned avoidance responding: Attenuation by prior training or by anticholinergic drugs. European Journal of Pharmacology, 30, 309-314.

Harrington, R. A., Hamilton, C. W., Brogden, R. N., Linkewich, J. A., Romankiewicz, J. A., \& HeEl, R. C. (1983). Metoclopramide: An updated review of its pharmacological properties and clinical use. Drugs, 25, 451-494.

Heybach, J. P., Coover, G. D., Lints, C. E. (1978). Behavioral effects of neurotoxic lesions of the ascending monoamine pathways in the rat brain. Journal of Comparative \& Physiological Psychology, $92,58-70$.

HIRSH, R. (1980). The hippocampus, conditional operations, and cognition. Physiological Psychology, 8, 175-182.

INDO, T., \& ANDO, K. (1982). Metoclopramide-induced Parkinsonism. Archives of Neurology, 39, 494-496.

Kimble, G. A., \& Perlmuter, L. C. (1970). The problem of volition. Psychological Review, 77, 361-384.

LeDoux, J. E., Iwata, J., Cicchetti, P., \& Reis, D. J. (1988). Different projections of the central amygdaloid nucleus mediate autonomic and behavioral correlates of conditioned fear. Joumal of Neuroscience, 8, 2517-2529.

LENARD, L. G., \& BEER, B. (1975). 6-hydroxydopamine and avoidance: Possible role of response suppression. Pharmacology, Biochemistry \& Behavior, 3, 873-878.
Mackintosh, N. J. (1974). The psychology of animal learning. New York: Academic Press.

Masterson, F. A., \& Crawford, M. (1982). The defense motivation system: A theory of avoidance behavior. Behavioral \& Brain Sciences, 5, 661-696

MineKA, S. (1979). The role of fear in theories of avoidance learning, flooding, and extinction. Psychological Bulletin, 86, 985-1010.

Mishicin, M., \& Petri, H. L. (1984). Memories and habits: Some implications for the analysis of learning and retention. In L. R. Squire \& N. Butters (Eds.), Neuropsychology of memory (pp. 287-296). New York: Guilford.

Mowrer, O. H. (1947). On the dual nature of learning: A reinterpretation of "conditioning" and "problem solving. "Harvard Educational Review, 17, 102-148.

Neill, D. B., Boggan, W. O., \& Grossman, S. P. (1974). Impairment of avoidance performance by intrastriatal administration of 6-hydroxydopamine. Pharmacology, Biochemistry \& Behavior, 2, 97-103.

O'KEEFE, J., \& NADEL, L. (1978). The hippocampus as a cognitive map. New York: Oxford University Press.

Overmier, J. B., \& Leaf, R. C. (1965). Effects of discriminative Pavlovian fear conditioning upon previously or subsequently acquired avoidance responses. Joumal of Comparative \& Physiological Psychology, 60, 213-217.

PosLuns, D. (1962). An analysis of chlorpromazine-induced suppression of the avoidance response. Psychopharmacologia, 3, 361-373.

Ray, O. S., \& Bivens, L. W. (1966). Performance as a function of drug, dose, and level of training. Psychopharmacologia, 10, 103-109.

Seligman, M. E. P., Johnston, J. C. (1973). A cognitive theory of avoidance learning. In F. J. McGuigan \& D. B. Lumsden (Eds.), Contemporary approaches to conditioning and learning (pp. 69-110). Toronto: Wiley.

ToAtes, F. M. (1982). A cognitive-incentive view. Behavioral \& Brain Sciences, 5, 683-684.

Weiss, J. M., Kriekhaus, E. E., \& ConTe, R. (1968). Effects of fear conditioning on subsequent avoidance behavior and movement. Joumal of Comparative \& Physiological Psychology, 65, 413-421.

\section{NOTES}

1. The terms "aversive stimulus" and "warning signal" are used here because they are operationally defined and theoretically neutral. The more common designations of "conditional stimulus" and "unconditional stimulus" are artefacts of an era when avoidance responses were viewed as Pavlovian conditioned responses (Bolles, 1972).

2. LeDoux, Iwata, Cicchetti, and Reis (1988) have recently demonstrated that conditioned changes in blood pressure and freezing involve projections of the central amygdaloid nucleus to, respectively, the lateral hypothalamus and the caudal portion of the central gray region.

(Manuscript received March 9, 1989; revision accepted for publication September 15, 1989.) 